\title{
Has China's Dairy Structural Adjustment Policy Achieved Its Goal?
}

\author{
Dao Rina \\ School of Economics and Management, Inner Mongolia University, China
}

Copyright $(2015$ by authors, all rights reserved. Authors agree that this article remains permanently open access under the terms of the Creative Commons Attribution License 4.0 International License

\begin{abstract}
A series of dairy structural adjustment (DSA) policies was introduced by the Chinese central government to restructure dairy farms after the 2008 melamine contamination scandal in China. This paper seeks to explore the impact of Chinese DSA policies on farm level structure change. There were three parts of this policy: (1) milk collectors' control; (2) manufacturers' raw milk supply source regulation; and (3) assistance to expand large-scale farms. This policy reform is oriented towards large-scale dairy farms. The purpose of this policy is to restructure dairy farms by reducing small-scale farms while promoting the large-scale farms. The results show that the Chinese DSA policy greatly increased the herd and outputs of the large-scale farms but failed to reduce the market dominance of small-scale farms. Also, this policy was not able to boost the market share of medium-scale farms as well as the per cow productivity of those farms. This research reveals an opportunity to further understand both the impact of and rationale for the policy, and shows that a rethink of the dairy industry development in China is required.
\end{abstract}

Keywords Chinese Dairy Structural Adjustment Policy, Dairy Farms, Impact

JEL Classification Codes: Q180, Q120

\section{Introduction}

China's milk production has experienced rapid growth in the past decades driven by increases in the number of cows and per head productivity. Total milk production has increased from 7.4 million tons in 1998 to 37.81 million tons in 2008, representing a fourfold increase. During the same period, the number of cows rose from 4.26 million to 12.33 million, and per head productivity increased from 2.82 tons to 4.8 tons, rising by 70.71 per cent from 10 years ago. However, 67.5 per cent of cows were raised by small-scale farms $(<20$ cows $)$ in 2008 . Those farms are the dominant producers in the Chinese milk market, comprising
97.6 per cent of nation's dairy farms. The numerous small-scale farms result in structural problems due to their low productivity and potential hazards of production, which increase the difficulty of food safety control by both of the manufacturers and the Chinese government [1]. The outbreak of the melamine contamination scandal highlighted major safety concerns in the dairy industry, prompting the central government to introduce a series of dairy reforms to restructure the industry rapidly. The dairy structural adjustment (DSA) policy was one reform aimed at restructuring dairy farms by reducing small-scale farms while promoting large-scale farms. There were three parts of this policy: (1) milk collectors' control; (2) manufacturers' raw milk supply source regulation; and (3) assistance to expand large-scale farms. What is the policy impact on farm level structural change, and can this policy achieve its goal? The answers to these questions can be seen in the form of structural changes i.e. farm number, head, milk production and per cow productivity by herd size.

The current literature on Chinese dairy policy reform introduced after the food safety crisis has concentrated on dairy industry regulations and dairy quality control. For example, research has examined the impact of dairy industry regulation on dairy enterprises' structure[2], and on the spatial distribution of milk collection stations of Inner Mongolia after the milk collector's governance[3]. The small-scale, scattered farms would be hurt by the milk scandal, which draws some concerns to estimate effects of the marketing and production management policies on small-scale dairy farmers $[4,5]$. However, few papers have been published on the implementation of the DSA policy, its funding and impact on farm structure change .The DSA policy is a significant part of post-scandal dairy reform in China. The objective of this article is to explore Chinese DSA polices to determine the impact on farm level structural change as a basis for further understanding the influence of the policy and for gaining some perspective about likely future development in the industry. In an effort to look into the DSA policy effect, the Ex-ante and Ex-post comparison analysis is conducted in this study. Major emphasis is placed on reviewing the changes evident on 
small-scale farms, which may affect the pace and direction of the evolution of farm structure.

The approach to this issue is divided into four main sections: (1) contextual review of the Chinese raw milk supply chain; (2) analysis of dairy structural adjustment policies; (3) the impacts of these policies on farm level structural changes; and (4) conclusions and policy implications.

\section{China's Raw Milk Supply Chain}

\subsection{Milk Producers}

China's raw milk supply chain consists of three major players: milk producers, milk collectors and manufacturers (Figure 1). Milk producers can be divided into four types in terms of their herd size and operations: small-scale backyard farms; small-scale farms cooperatives; medium-scale farms dairy plots; and large-scale farms. Small-scale backyard farms with fewer than 20 cows, where animals are fed in stanchion barns, heavily or entirely relied on the family growing feed, and have been described as a "potentially hazardous mode of production" [1, p. 170].
Small-scale farm cooperatives are essentially a collaboration of small-scale farms with 10 to 20 cows. Unlike small-scale backyard farms, farms cooperatives' cows are fed in corrals often built by the village committee and managed by the cooperatives. The objective of these cooperatives is to improve the market power of small-scale farms in milk selling hereby getting a higher price from the dairy manufactures. Compared with dairy cooperatives, the dairy plots are well-designed 'dairy zones' invested in by the local government or the manufacturers, with free feeding capacities and standard milking facilities. The purpose of these dairy zones is to promote the concentration of the medium-scale farms (e.g. from 20 to 200 cows) for securing milk supplies. In the dairy zone, cows are raised by individual farms but managed by the dairy plots. While the large-scale operations, which have more than 200 cows, generally accompanied by a confinement production system, are described as industrial or factory farms. The cows are confined in their own free-stall barns and milked in a milking parlour. In addition, with the exception of small-scale backyard farms, all the dairy operations have milking facilities built in their farming area, but may not be owned by the individual dairy farm.

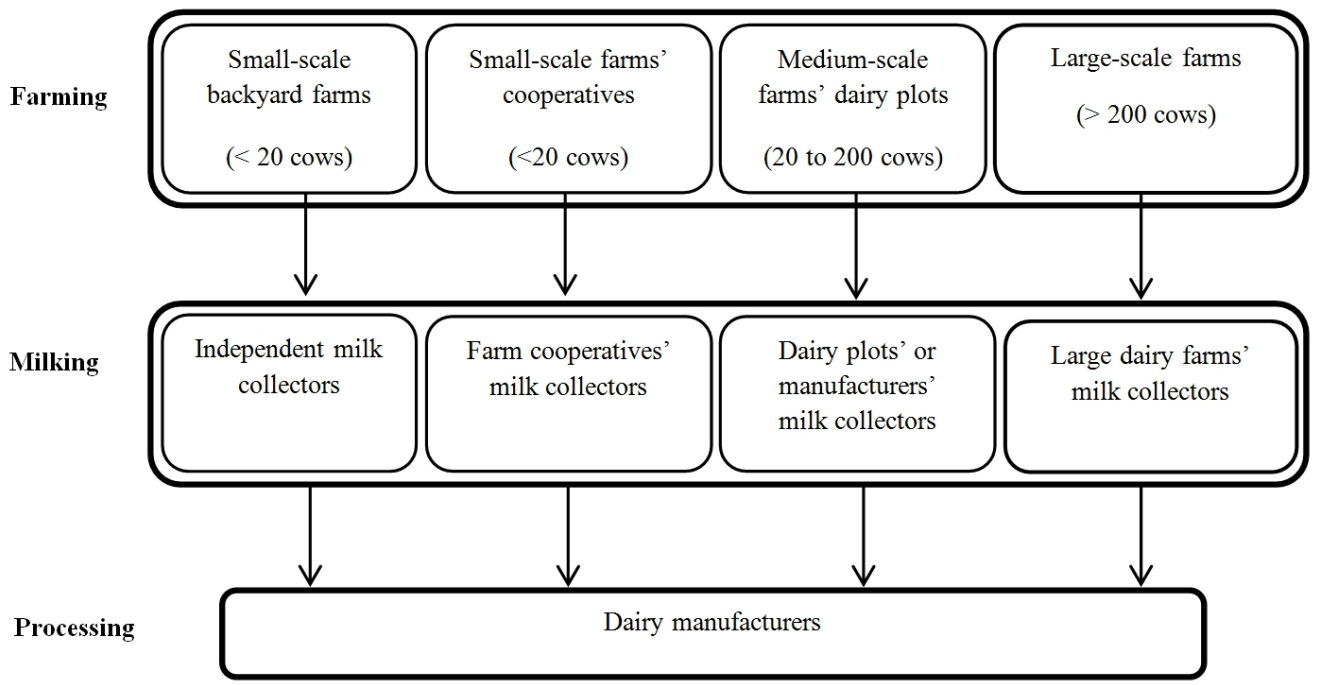

Figure 1. China's raw milk supply chain

Table 1. Herd Size Distribution of Chinese Dairy Farms 2008

\begin{tabular}{ccccccc}
\hline Herd size & $\begin{array}{c}\text { No. } \\
\text { of farms }\end{array}$ & Share (\%) & $\begin{array}{c}\text { No. } \\
\text { of cows }\end{array}$ & Share (\%) & $\begin{array}{c}\text { Milk production } \\
\text { (ton) }\end{array}$ & $\begin{array}{c}\text { Share } \\
(\%)\end{array}$ \\
\hline $1-4$ cows & $2,159,701$ & 80.93 & $5,942,220$ & 39.73 & $9,810,764$ & 25.06 \\
$5-19$ cows & 444,895 & 16.67 & $4,160,598$ & 27.82 & $12,478,123$ & 31.87 \\
$20-99$ cows & 56,254 & 2.11 & $2,409,332$ & 16.11 & $7,092,837$ & 18.12 \\
$100-199$ cows & 4,421 & 0.17 & 634,835 & 4.24 & $1,925,349$ & 4.92 \\
$200-499$ cows & 2,336 & 0.09 & 696,967 & 4.66 & $2,680,272$ & 6.85 \\
$500-999$ cows & 768 & 0.03 & 526,927 & 3.52 & $2,287,433$ & 5.84 \\
1000 and over cows & 339 & 0.01 & 586,749 & 3.92 & $2,875,153$ & 7.34 \\
Total & $2,668,714$ & 100 & $14,957,628$ & 100 & $39,149,931$ & 100 \\
\hline
\end{tabular}

Source: Chinese Dairy Year Book (2009). 
China's milk production has been dominated by small-scale farms, as indicated in Table 1; they comprised 97.3 per cent of total farms and 67.55 per cent of the nation's cows in 2008. The amount of small-scale farms' cooperatives is so small that they only accounted for 0.024 per cent of total small-scale farms in 2008. Medium-scale farms comprised only 2.28 per cent of all farms, had 20.35 per cent of total cows and produced 23.04 per cent of nation's milk in 2008. Large-scale farms represented only a tiny percentage of all farms, with 0.13 per cent, but they milked 12.1 per cent of the nation's cows and constituted 20.03 per cent of milk production in 2008. This highlights the structural imbalance of Chinese dairy farms, which prompted the central government to restructure dairy farms by reducing small-scale farms while promoting large-scale farms.

\subsection{Milk Collectors}

Milk collectors are the owners of milking facilities who undertake milking, measuring and delivery. They provide transaction services for both producers and dairy processors, and get paid by dairy processors in terms of the quantity and quality of milk delivered. The ownership of milk collectors are diversified within dairy operations, and are classified into five groups: (1) milk collectors owned by independent investors; (2) operated by farmers' cooperatives; (3) managed by dairy manufacturers; (4) run by dairy plots; and (5) owned by large-scale dairy farms. Usually, independent milk collectors serve the small-scale backyard farms, while the manufacturers' and dairy plots' collectors are responsible for the dairy plots. Those in the farmer's cooperatives' and large-scale farms work for themselves.

Milk transactions in China have been led by independent milk collectors, who constituted 63 per cent of the total in 2008 .While except the small percentage of 1.8 farms cooperatives' milk collectors, all of the small-scale farms' cows were milked by those independent collectors (Table 2). However, due to the manufacturers' poor supervision, incentive deviation, and unreasonable profit distribution, the rise of fraudulent independent milk collectors appears to have been unavoidable [6-8]. The 2008 melamine crisis confirmed the misconduct of unscrupulous independent milk collectors, causing the central government to regulate milk collectors and therefore to restructure dairy farms.

\subsection{Dairy Manufacturers}

Dairy manufacturers convert and package the raw milk into various final milk products for consumption, including drinkable liquid milks, ice creams, powders, etc. Dairy manufacturers in China grow rapidly in the past decade (Table 3). There were 815 dairy manufacturers with an annual income of over 5 million Yuan in 2008. However, only 9 manufacturers are large-scale firms with annual revenue more than 500 million Yuan in annual sales. The medium-scale manufacturers with annual revenue from 50 million to 500 million Yuan in sales, consisted of 137 companies which constituted 16.8 per cent of the whole industry. While small-scale enterprises were the largest group, totally 669 companies making up 82.1 per cent of all processors. Large amount of small-scale manufacturers can easily lead to over production, therefore hardly maintain the stable relationship with the milk producers. The major large processors are dominant in both input and output markets, which given them a level of economic importance in the local economy. As a result, small dairy farms, milk collectors and even governments have developed a state of dependency on their continued profitability and growth[9].

Economics of scale combined with marketing power in both input and output markets have allowed the large manufacturers to pursue aggressive growth strategies. They tend to use their market power both in milk pricing and milk quality testing. Specifically, they adjust milk prices according to demand for milk and to change the strictness of quality testing depending on the milk output [10]. An example is during the winter, when the milk supply is low the quality testing is relaxed to avoid a shortage. Due to the dominance of manufacturing in the supply chain, the government used this sector to enforce the dairy farm structural adjustment policy.

Table 2. Ownership Structure of Milk Collectors in China 2008

\begin{tabular}{ccccccc}
\hline & Manufacturers & $\begin{array}{c}\text { Large-scale dairy } \\
\text { farms }\end{array}$ & Dairy plots & $\begin{array}{c}\text { Independent } \\
\text { investors }\end{array}$ & $\begin{array}{c}\text { Farms } \\
\text { cooperatives }\end{array}$ & Total \\
\hline Number & 2036 & 2395 & 2758 & 12841 & 636 & 20,393 \\
Share (\%) & 10.00 & 11.70 & 13.50 & 63.00 & 1.80 & 100.00 \\
\hline
\end{tabular}

Source: Qian, et al. (2011)

Table 3. Size Distribution of Dairy Manufacturers in Chinese Dairy Industry 2000-2008

\begin{tabular}{|c|c|c|c|c|c|c|c|c|c|}
\hline & 2000 & 2001 & 2002 & 2003 & 2004 & 2005 & 2006 & 2007 & 2008 \\
\hline Total dairy manufacturers & 377 & 434 & 499 & 584 & 636 & 690 & 717 & 736 & 815 \\
\hline Large-scale & 33 & 33 & 36 & 9 & 8 & 10 & 9 & 12 & 9 \\
\hline Medium-scale & 39 & 46 & 46 & 88 & 85 & 109 & 107 & 126 & 137 \\
\hline Small-scale & 305 & 355 & 417 & 487 & 543 & 579 & 601 & 598 & 669 \\
\hline
\end{tabular}

Source: Chinese Dairy Year Book (2009). 


\section{The Dairy Structural Adjustment Policy}

\subsection{Milk Collector Control}

The DSA policy had three components: (1) milk collectors control[11]; (2) manufacturers' raw milk supply source regulation[12]; and (3) scale expansion assistance for large-scale dairy farms [13]. Milk collector governance came first, shortly after the melamine crisis. This policy aimed to rectify the misconduct of milk collectors by eliminating independent milk collectors. It was implemented in two steps: (1) accreditate milk collectors owned by farmer cooperatives, manufacturers and large dairy farms; and (2) terminate independent milk collectors. The independent milk collectors act as principle links between small-scale farms and dairy manufacturers. They have played a significant role in raw milk supply chain over the past decades. However, the elimination of those collectors will drive the small-scale farms out of the market by cutting off their links with manufacturers and leaving those farms with no buyers for their output. While there was no evidence the melamine contamination scandal was caused by small-scale farms they had no option but to dump their milk as government policy makers sought to restructure the nation's dairy industry [4]. Apparently, milk collector control is an irrational regulation but the discussion of this is beyond the scope of this research.

\subsection{Manufacturers' Raw Milk Supply Regulation}

Manufacturers' raw milk supply regulation was used to secure high-quality raw milk supply by restricting purchase from small-scale farms. This regulation consisted of two items: first the reliable raw milk suppliers were declared; second the share of reliable raw milk supply was specified. In this regulation, the following agents are regarded as reliable raw milk suppliers: dairy farms operated by manufacturers, farmers cooperatives, and large-scale farms as well as raw milk delivered from certified milk collectors. Small-scale farms were not regarded as reliable suppliers, therefore were excluded from these agents. Regulation further confirmed that milk from the above agents ought to share no less than 70 per cent of total raw milk supply for all manufacturers until the end of October 2011. The raw milk supply share control is to restrict manufacturers' access to milk from small-scale farms, and thereby drive these farms out of the market. The 70 percent target indicates a clear intention for large capital investments for large scale farms. The assumption being made by the government is this investment coincides with improved safety and sustainability, which has not been tested yet. Furthermore, there is no evidence can be found that the small-scale farms were not able to produce good milk.

\subsection{Scale Expansion Assistance for Dairy Farms}

In January 2009, money was provided by the central government to assist large dairy farms scale expansion. The grants totaled 2.5 billion Yuan over a five year period, from 2009 to 2014. Farms with more than 200 cows could apply for the grants. The entitlements were coupled with farm size: the larger the farm, the greater the funding. This was achieved by dividing the farms into three groups: (1) farms with 200 to 499 cows to receive 0.5 million Yuan; (2) farms with 500 to 1000 cows to receive 1 million Yuan; and (3) more than 1000 cows mega-dairies entitled to 1.5 million Yuan. By nurturing the large-scale farms, the government set a target of 30 per cent of the nation's cows expected to be milked by both medium-scale farms with 100 to 200 cows and large-scale farms with more than 200 cows until the end of October 2011. However, a lack of assistance to medium-scale farms with 100 to 200 cows highlights the inconsistence with the government's grants and goal. This inconsistence of government's grant and goal reflect the fact that the Chinese government tends to restructure dairy farms by setting a higher goal while spending less money. The possible reason of this higher goal would be due to the government aiming to rebuild its public trust level which was reduced by the dairy safety crisis [14]. However an unanswered questions remains, how would this goal will be able to promote the long-term dairy safety and supply sustainability in the dairy industry, even if it can be achieved.

\section{Farm Level Structure Change: The Ex-ante and Ex-post Comparison Analysis}

To look into the DSA policy impact on farm level structural change, the ex-ante and ex-post comparison analysis is developed. Farm level structural change is identified in terms with the changes of the number, heads and milk output as well as the per cow productivity of farms.

\subsection{The Number of Farms}

The number of small-scale farms has declined substantially since the dairy structural adjustment policy (Table 4) (e.g. falling by 617,700 farms or 24.01 per cent between 2008 and 2011).There are several reasons for this decline; firstly, the termination of the independent milk collectors cut off the links between small-scale farms and dairy manufacturers, and then caused small-scale farms to leave the market [15]. It was reported that 6,890 independent milk collectors had been eliminated since 2008, yet the total number of those declined by 34 per cent to 13,503 [16]. Secondly the strengthening of the raw milk quality testing of manufacturers reduced milk purchasing from small-scale farms driving them out of the milk production [15]. Coupled with an increase in cattle feed prices, small-scale farms could not earn an income; hence, 
they exited the market [6].

Medium-scale farms with 20 to 200 cows increased greatly, rising by 17.2 per cent between 2008 and 2011 (Table 4).The major increase occurred in 20 to 99 cow farms which accounted for 86.6 per cent of growth. Possible reason of this are: rising milk prices after 2008, small-scale farm expansion or independent milk collectors make a transition to dairy farm cooperatives by setting up shelters to concentrate nearby small-scale farms (Jia. et al. call it cows hotel). The 100 to 199 cow farms rose by only 811 farms, or shared 13.4 percent of the increase, and this did not meet the government's expectation of 30 per cent of cow inventory share of more than 100-cow farms. The small changes occurred in 100 to 199 cows farms indicates another significant issue that the DSA policy had ignored those farms since it was implemented.

By contrast, large-scale farms with more than 200 cows grew dramatically since the DSA policy, rising by 88.97 per cent between 2008 and 2011. Dairy farm scale expansion assistance may contribute to this increase [C.News, 17]. Also the dairy manufacturers increased their investment in large dairy farms to improve dairy safety after the melamine contamination event. Several media outlets claimed that the dairy enterprises, such as China Mengniu Dairy and Inner Mongolia Yili Group, both had spent 1.4 billion and 2.1 billion Chinese Yuan on large dairy farming, respectively $[18,19]$.

However, small-scale farms still accounted for 95.5 per cent of total dairy farms in 2011 (Fig. 2.). The proportion of these farms fell by only 1.58 per cent between 2008 and 2011. Medium-scale farms accounted for 4.1 per cent and large-scale farms only share 0.35 per cent of total farms in 2011, far less than the small-scale farms. This indicates that large-scale farm-oriented DSA policy was not able to change the small scale farms dominated farm structure.

Table 4. Change in Number of Farms by Herd Size Category, Chinese Dairy Industry 2008-11

\begin{tabular}{cccccccc}
\hline $\begin{array}{c}1-4 \\
\text { cows }\end{array}$ & $\begin{array}{c}5-19 \\
\text { cows }\end{array}$ & $\begin{array}{c}20-99 \\
\text { cows }\end{array}$ & $\begin{array}{c}100-199 \\
\text { cows }\end{array}$ & $\begin{array}{c}200-499 \\
\text { cows }\end{array}$ & $\begin{array}{c}500-999 \\
\text { cows }\end{array}$ & $\begin{array}{c}1000 \text {-plus } \\
\text { cows }\end{array}$ \\
\hline 2008 & 1970755 & 542102 & 65646 & 4425 & 2679 & 1026 & 454 \\
\hline 2009 & 1796061 & 506449 & 62840 & 4324 & 3341 & 1773 & 706 \\
\hline 2010 & 1750895 & 483913 & 64208 & 4604 & 3579 & 2061 & 898 \\
\hline 2011 & 1440970 & 454167 & 76145 & 5236 & 3930 & 2084 & 1016 \\
\hline
\end{tabular}

Source: Chinese Dairy Year Book (2009-12)

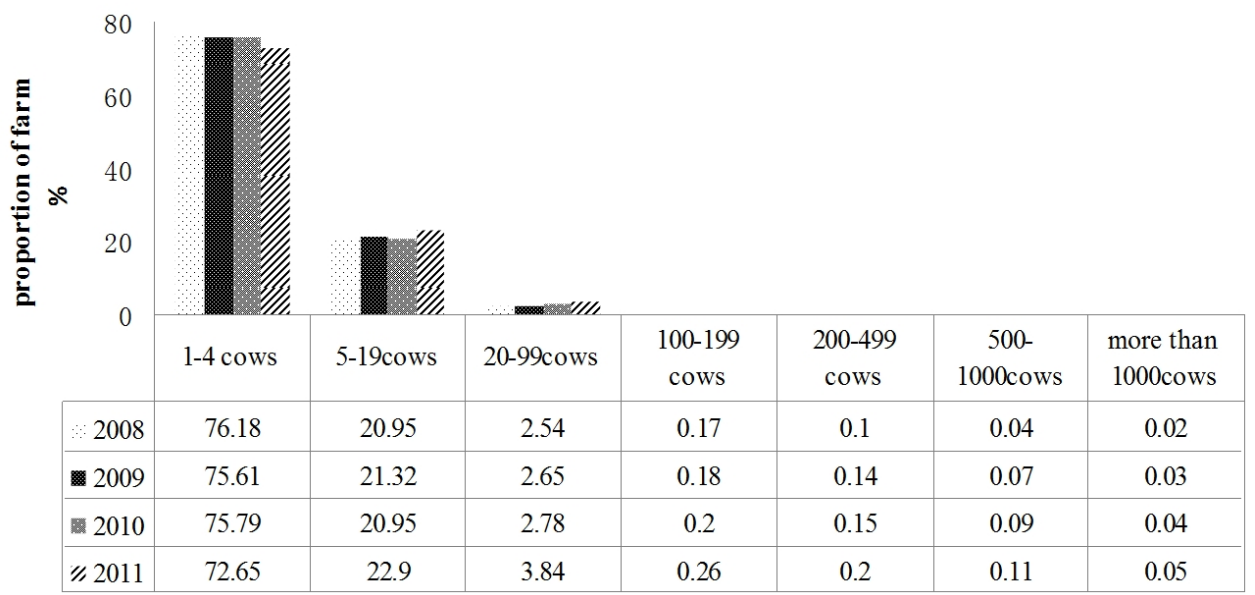

Source: Chinese dairy year book.

Figure 2. Change in Proportion of Farms by Herd Size Category, Chinese Dairy Industry 2011

Table 5. Change in Number of Cows by Herd Size Category, Chinese Dairy Industry 2008-11

\begin{tabular}{cccccccc}
\hline $\begin{array}{c}1-4 \\
\text { cows }\end{array}$ & $\begin{array}{c}5-19 \\
\text { cows }\end{array}$ & $\begin{array}{c}20-99 \\
\text { cows }\end{array}$ & $\begin{array}{c}100-199 \\
\text { cows }\end{array}$ & $\begin{array}{c}200-499 \\
\text { cows }\end{array}$ & $\begin{array}{c}500-1000 \\
\text { cows }\end{array}$ & $\begin{array}{c}1000 \text { plus } \\
\text { cows }\end{array}$ \\
\hline 2008 & 4966506 & 4829121 & 2529327 & 628186 & 835462 & 690573 & 849137 \\
\hline 2009 & 4415783 & 4605789 & 2476409 & 622298 & 1070472 & 1234833 & 1306106 \\
2010 & 4339471 & 4451121 & 2606054 & 674988 & 1164795 & 1475398 & 1716073 \\
2011 & 4199104 & 4315423 & 3165044 & 779623 & 1320904 & 1520926 & 2100491 \\
\hline
\end{tabular}

Source: Chinese Dairy Year Book (2009-12). 


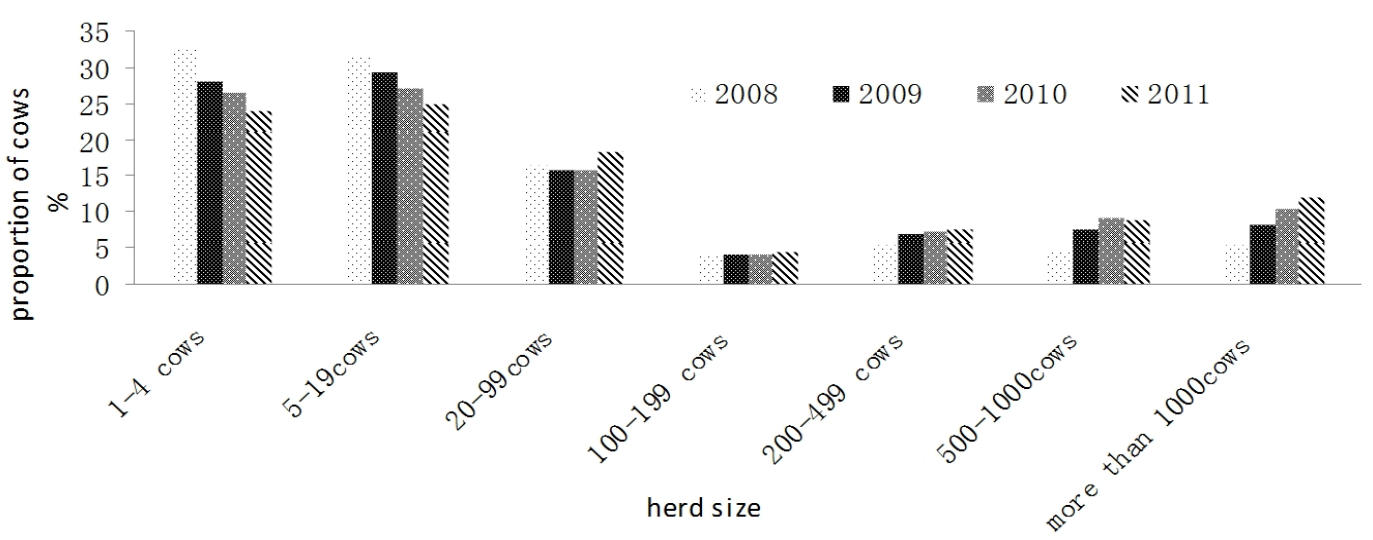

Source: Chinese dairy year book.

Figure 3. Change in Proportion of Cows by Herd Size Category, Chinese Dairy Industry 2008-11

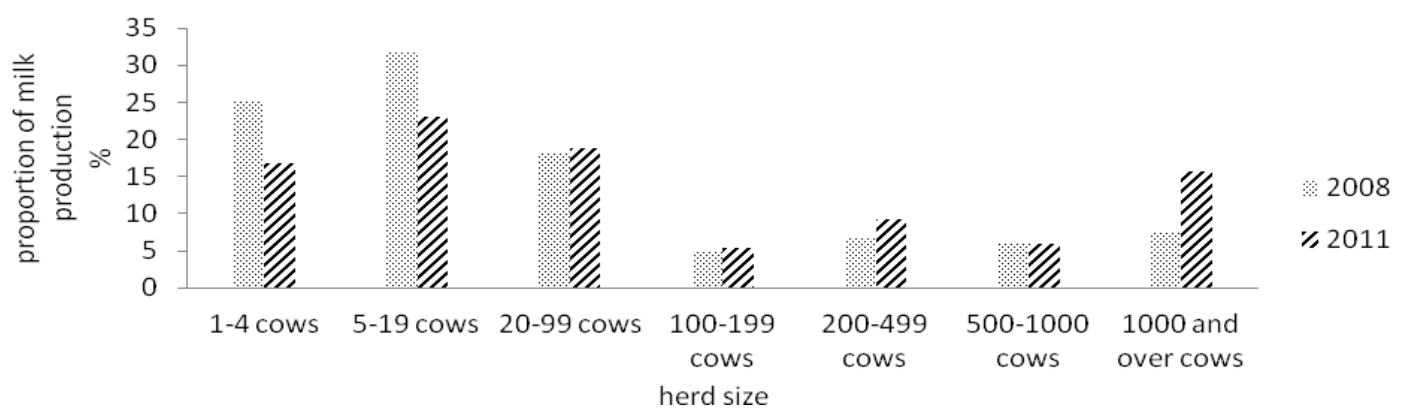

Source: Chinese dairy year book.

Figure 4. Change in Share of Milk Production by Herd Size Category, Chinese Dairy Industry 2008-11

\subsection{The Heads of Farms}

The total cows on small-scale farms declined substantially between 2008 and 2011, falling by 1.28 million cows or 15 per cent (Table 5). But these small farms still had 48.9 per cent of the nation's milk cows, and continue to be the largest holder (Fig. 3.).

The total cows on large-scale farms jumped from 2.38 million to 4.94 million, growing by 2.56 million, more than double between 2008 and 2011. These farms accounted for 28.4 per cent of the nation's cows, becoming the second largest holder in 2011(Fig. 3.).

By contrast, medium-scale farms only saw a small increase in total cows by 0.78 million heads over the same period. Priority was given to the 20 to 99 cow farms, which shared 80.76 per cent of the total increase, and 100 to 199 cow farms that contribute to only 19.24 per cent of it. Those farms with 100 to 199 cows accounted for only 4.48 per cent of total cows in 2011, but together with the large-scale dairy farms, both of them accounted for over 32.88 per cent of the nation's cow inventory in 2011 , and reached the government's re-set target of 30 per cent in scale expansion assistance program.

\subsection{Milk Production of Farms}

The total production of small dairy farms has dropped significantly since the DSA policy, falling from 22.28 million tons in 2008 to 18.74 million tons in 2011, a fall of 3.54 million tons or 15.91 per cent (Table 6).Despite this, small farms produced 39.71 per cent of the nation's milk in 2011, still as the leading producer of all farms (Fig. 4.). This demonstrates that the government's goal of 70 per cent of high-quality raw milk supply share control was not achieved until 2011.

The largest increase of milk production was among the large dairy farms, growing from 7.84 million tons to 17.7 million tons, rising by 9.22 million tons or doubled between 2008 and 2011. They produced as much as 36.18 per cent of nation's milk in 2011, but still less than the small farms.

By contrast, medium-scale farms saw a small increase of 2.36 million tons in milk production between 2008 and 2011. They produced 24.11 per cent of nation's milk in 2011 , which only increased by 1.07 per cent between 2008 and 2011. These results indicate that the dairy structural adjustment policy did not boost the medium-scale farms' milk production and market share. 
Table 6. Change in Milk Production by Herd Size Category, Chinese Dairy Industry 2008-11

\begin{tabular}{|c|c|c|c|c|c|c|c|c|}
\hline & $\begin{array}{c}1-4 \\
\text { cows }\end{array}$ & $\begin{array}{l}5-19 \\
\text { cows }\end{array}$ & $\begin{array}{l}20-99 \\
\text { cows }\end{array}$ & $\begin{array}{c}100-199 \\
\text { cows }\end{array}$ & $\begin{array}{c}200-499 \\
\text { cows }\end{array}$ & $\begin{array}{c}500-1000 \\
\text { cows }\end{array}$ & $\begin{array}{c}1000 \text { plus } \\
\text { cows }\end{array}$ & Total \\
\hline 2008 & 9.81 & 12.48 & 7.09 & 1.93 & 2.68 & 2.29 & 2.88 & 39.15 \\
\hline 2011 & 7.91 & 10.83 & 8.87 & 2.51 & 4.39 & 5.27 & 7.41 & 47.19 \\
\hline
\end{tabular}

Source: Chinese Dairy Year Book (2012).

Table 7. Change in Per Head Productivity by Herd Size Category, Chinese Dairy Industry 2008-11

\begin{tabular}{|c|c|c|c|c|c|c|c|}
\hline & 1-4 cows & 5-19cows & 20-99cows & 100-199 cows & $200-499$ cows & 500-1000cows & $\begin{array}{l}\text { more than } \\
1000 \text { cows }\end{array}$ \\
\hline 2008 & 3.29 & 4.31 & 4.67 & 5.11 & 5.35 & 5.52 & 5.64 \\
\hline 2011 & 3.14 & 4.18 & 4.67 & 5.36 & 5.54 & 5.78 & 5.88 \\
\hline
\end{tabular}

Source: Chinese Dairy Year Book(2008-2012)

\subsection{Per Head Productivity of Farms}

The less than 20 cows small-scale farms witnessed a decline in per head productivity between 2008 and 2011. The small-scale backyard farms' ( $<5$ cows) per head productivity fell from 3.29 ton to 3.14 ton, while 5 to 19 cows farms fell from 4.31 ton to 4.18 ton respectively (Table 7). This indicates that the DSA policy was not able to improve the per cows productivity of small-scale farms. The lower productivity of small-scale farms had already been the main issue for China's milk production, which raise much concern in dairy economic field $[1,20,21]$

The 20 to 99 cows medium scale farms' per cow output seems to be caught in a "fixed amount of 4.67 ton", with no changes in their productivity between 2008 and 2011. However, the more than 100 cows farms all saw an increase in per cow productivity during the same period. The large-scale farms expansion assistance may contribute to this increase, while the net effect of this policy needs to be further identified.

By contrast, the more than 1000 cows mega-dairies enjoyed the highest per cow productivity of 5.88 ton in 2011 , increasing by 4.25 per cent between 2008 and 2011. The per head yield of small-scale farms, however, decreased by 4.55 per cent over the same period. Consequently, productivity inequality between small and large farmers keeps increasing, which becomes a structural problem in Chinese milk production, and considered as an important driving force behind the melamine contamination scandal in 2008[1]. For this reason, the DSA policy may not be able to promote dairy safety as the policy makers expected.

\section{Conclusions and Policy Implications}

\subsection{Conclusions}

The purpose of this research is to analyse the impact of China's dairy structural adjustment (DSA) policy on farm level structure change, including the number of farms, heads, milk production and per cow productivity by herd size category. China's DSA policy is oriented toward large dairy farms. The objective of this policy is to restructure dairy farms by reducing small-scale farms while promoting large-scale farms. But it has failed to comprehensively achieve its goal because it was not able to reduce the market dominance of small-scale farms. Small-scale farms still dominate the dairy landscape and play an important role in both cow feeding and milk production. Also, the DSA policy was not able to boost the milk market share of medium-scale farms. Again, the DSA policy increased the productivity inequality between small and large farmers, hence exacerbated the structural problem in China's milk production. Although the herds and the output of large dairies had increased substantially since the introduction of the dairy structural adjustment policy, they only constituted of 0.37 per cent of total farms and 28.4 per cent of the nation's cows. The failure of the current policy requires a rethink of the development of Chinese dairy industry.

\subsection{Policy Implications}

China's dairy industry faces challenges of both food safety and supply sustainability in the course of rapid expansion. Chinese government has to deal with these challenges swiftly to alleviate or avoid supply shortage and further food safety crises in the future. Sufficient supervision and the implementation of more efficient dairy safety regulations for the overall milk supply chain are required to ensure food safety. Firstly the dairy plots milk collectors should be certified to reduce dairy safety hazard generated by this operations. Secondly the transition of independent milk collectors into farmer's cooperatives needs to be further promoted. Thirdly the security of high quality raw milk supply systems needs to be established at the farm level, not only during the manufacturing level.

Furthermore, the Chinese government should provide more opportunities and support to medium-scale farms through changes in policy and reallocation of resources to encourage them to expand by acquisitions. This direction 
might encourage medium-scale farms to consolidate with small-scale farms become the large-scale farms; or assist the independent milk collectors in combining with nearby small-scale farms to establish farms cooperatives.

Also, small-scale farms need to be considered and exit assistance in particular is required to help marginal small-scale farms to exit the industry. Specifically, the small-scale farmers, who exit the dairy market should be assisted in terms of the number of cows they milked during the assistance period. The exit farmers then should be provided with some career training program to start a new business or get employed in the new market.

\section{Acknowledgements}

The research documented in this paper was undertaken while the author was a visiting researcher at the school of business James Cook University, Australia. She is grateful for the opportunity provided by James Cook University, and for research assistance provided by the China Scholarship Council. The author has benefitted from discussions with, and suggestions from, Professor Zhang Yue Zhou, Dr Hong Bo Liu, Dr Liz Tynan and Christopher Nicholas.

\section{REFERENCES}

[1] Yu, X.H., Productivity, Efficiency and Structural Problems in Chinese Dairy Farms, . China Agricultural Economic Review 2012. 4(2): p. 168-175.

[2] Chen, Y., Dairy Industry Restructuring and New Policy Reform. China Dairy 2011. 113: p. 2-4.

[3] Qian, G.X., Xiao, M., Zhao, W. Z., Zhang, Q. F., and P, Y.H., China's Dairy Crisis: Impacts, Causes and Policy Implications for Sustainable Dairy Industry, . Journal of Agricultural Science and Technology 2013. 15(4): p. 102-109.

[4] Jia, X.,Huang,J., Luan.H.,Rozello.S.,Swinnen.J., China’s Milk Scandal, government policy and production decisions of dairyfarmers: The case of Greater Beijing. Food Policy, 2012. 37(4): p. 390-400.

[5] Mo, D., Huang,J., Jia.,X., Luan.H.,Rozello.S.,Swinnen.J., Checking into China's cow hotels: Have policies following the milk scandal changed the structure of the dairy sector? Journal of Dairy Science, 2012. 95(5): p. 2282-2298.

[6] Kong, X., Zhong, Zhen, Economics Explanations on the Quality Control of Milk Stations. Issues in Agricultural Economy, 2009(9): p. 24-29.

[7] Li, J., The Effectiveness of Chinese Food Safety Supervision System: Based on the Investigation of China's Dairy Industry. Wu Han University Journal (Philosophy \& Social Sciences) 2011. 64(2): p. 88-91.
[8] Dao, R.N., Milk Collector's Incentive Deviation and Optimal Incentive Contract: based on the Multitask Principle-agent Model, . Research of Agricultural Modernization 2012. 33(4): p. 435-439.

[9] Xiu, C. and K.K. Klein, Melamine in milk products in China: Examining the factors that led to deliberate use of the contaminant. Food Policy, 2010. 35(5): p. 463-470.

[10] Dao, R.N., The Transaction Relationship Between Dairy Enterprise and Dairy Farmers. Journal of Huazhong Normal University (Humanities and Social Sciences),, 2008. 47(4): p. 57-62.

[11] Council, G.O.o.t.S., Dairy industry Consolidation and Revitalization Program Guidelines, 2008.

[12] Ministry of Agriculture [MA], M.o.I.a.I.T.M., Ministry of Public Security [MPS], Ministry of Health[MH], the State Administration of Industry and Commerce [SAIC], and General Administration of Quality Supervision [GAQS], . Specific Rectification of Milk Collection Stations, . 2008 [cited 2008 September 23]; Available from: http://ghs.miit.gov.cn/n11293472/n11293877/n11301970/n1 1552553/11554319.html.

[13] Gao, H., Change the Development Pattern of Dairy Industry and Ensuring Dairy Safety in the Second Chinese Dairy Conference. 2011, Ministry of Agriculture Hefei, Anhui Province.

[14] Wang, C.X., Regulation Failure, Public Expectation Adjustment and Low Trust Level: An Empirical Analysis of Quality Supervision of Dairy Industry. Macroeconomic Study, 2011(2): p. 31-35.

[15] Dao, R.N., Risk Aversion and Dairy farmers Exit,. Chinese Journal of Animal Science, 2013. 49(20): p. 52-57.

[16] Feng, h., Experts' Points of View on raw milk supply chain management: Nationwide Milk Collectors are Under Supervision, in China Daily. 2011.

[17] Chinairn, N. Current Situation and Scale Expansion Process of Chinese Dairy Industry 2012. Available from http://www.chinairn.com/news/20120223/238153.html

[18] News, I. Great Leap Forward of Dairy Safety: Losterand Winner 2013. Available from http://blog.fashion.ifeng.com/article/23710240.html

[19] News, C., The Hidden Pollution Crisis: Great Leap Forward to Mega-dairies in China's Dairy Farming 2013. Available from

http://finance.ifeng.com/news/industry/20120112/5439556.s html

[20] Ma, H., Rae, Allan N., Huang,J., Rozelle, S., Enhancing productivity on suburban dairy farms in China. Agricultural Economics, 2007. 37(1): p. 29-42.

[21] Cao, J., Chinese dairy farms' economic efficiency analysis. China Rural Economy, 2005(2): p. 201-215. 